\title{
Recent advances in
}

\section{electroconvulsive therapy and physical treatments for depression}

\author{
I. Nicol Ferrier $(D$, Jonathan Waite \& Vimal Sivasanker
}

\begin{abstract}
SUMMARY
This article gives an update for practitioners on recent developments in the use of electroconvulsive therapy (ECT) and related treatment modalities in the contemporary treatment of depression in the UK. Details are provided on new information on the efficacy and side-effects of ECT both in research studies and in the real world, together with recent research on ECT's mode of delivery. There is a focus on the safe administration of ECT in clinical practice. An update on the regulatory framework for ECT in the UK is provided, together with upto-date information on the legal situation regarding its prescription. Finally, brief summaries of the current position for other neuromodulatory treatment modalities are given.
\end{abstract}

\section{LEARNING OBJECTIVES}

After reading this article you will be able to:

- understand the evidence that supports the continuing use of ECT in contemporary psychiatry

- recognise and assess the adverse effects of physical treatment for depression

- make rational decisions on the clinical use of ECT and related physical treatments.

\section{KEYWORDS}

Electroconvulsive therapy; depressive disorders; psychiatry and law; clinical governance; neurophysiology.

This article is a non-systematic review of recent research on the efficacy and safe administration of electroconvulsive therapy (ECT) and other neuromodulatory modalities in depression. More detail and background on all these topics can be found in the recently published 4th edition of The ECT Handbook (Ferrier 2019). That volume also reports details of the growing evidence base for the safe and effective use of ECT in other conditions, such as depression in bipolar disorder, mania, catatonia, clozapine-resistant schizophrenia and certain neuropsychiatric disorders, although randomised controlled trials (RCTs) are few in number for these conditions. Randomised and non-randomised evidence on the use of ECT in particular patient groups, such as the elderly, children and adolescents (including those with intellectual disability or challenging behaviour) and those with medical comorbidities and in pregnancy and the puerperium, is also reviewed in the new Handbook but is outside the scope of this article.

\section{ECT in depression}

Two large meta-analyses concluded that ECT is the most effective short-term treatment for major depression (UK ECT Review Group 2003; Pagnin 2004). More recently, it has been shown that ECT is associated with a good return to function and quality of life (Rosenquist 2006). Reports from the ECT Accreditation Service (ECTAS) and the Scottish ECT Accreditation Network (SEAN) bodies that monitor ECT in England and Wales and in Scotland - confirm these findings and indicate the effectiveness of ECT as currently administered in the UK (Buley 2017; Scottish ECT Accreditation Network 2019; ECT Accreditation Service 2020a). The findings of these nationwide comprehensive audits have been consistent for at least a decade and indicate that the findings of RCTs reported below are mirrored in the real world.

Remission rates of around $60-80 \%$ have been reported when ECT is used as first-line treatment in a severe depressive episode and rates are even higher in psychotic depression (Petrides 2001). Remission rates are high in elderly people, who also show a more rapid response (Spaans 2015). Kellner et al (2005) demonstrated the efficacy of ECT in depression with suicidal features, with a substantial and rapid reduction in the expression of suicidal thoughts.

ECT is safe even in those with medical illnesses and should not be relegated to a treatment of last resort. In 2018, after a comprehensive review of scientific data and more than 3400 submissions, the US Food and Drug Administration (FDA) considered that the balance of safety and risks was such that ECT machines were downgraded from class III (high risk) to class II (moderate), although with
I. Nicol Ferrier, BSc, FRCPsych, FRCP(Ed), MD (Hons), is Emeritus Professor of Psychiatry at Newcastle University, Newcastle upon Tyne, UK. He was Professor of Psychiatry at Newcastle University from 1990 to 2014, is a past President of the British Association for Psychopharmacology, and was Chair of the ECT and Related Treatments Committee (2015-2019). He is co-editor of The ECT Handbook (4th edn). His clinical and research interests are in severe affective disorders. Jonathan Waite, BSc, MB ChB, FRCPsych, LLM, is a locum consultant in the psychiatry of old age with Nottinghamshire Healthcare NHS Foundation Trust and an Honorary Senior Fellow at the Institute of Mental Health, University of Nottingham, UK. He is a co-author of Dementia Care: A Practical Manual (Oxford University Press 2009) and co-editor of The ECT Handbook (3rd and 4th edns). Vimal Sivasanker, MA, MBBS, FRCPsych, is a consultant in general adult psychiatry and lead consultant for ECT with Hertfordshire Partnership University NHS Foundation Trust, UK. He has been working in ECT services for 15 years. He has an interest in ECT training and has revised the Royal College of Psychiatrists' Good Practice Guide to ECT Training (RCPsych 2018) and contributed on ECT training to The ECT Handbook He was Vice-Chair of the ECT and Related Treatments Committee (2014-2019) and is the current Chair of the Royal College of Psychiatrists' ECT Accreditation Service (ECTAS) Advisory Group.

Correspondence I. Nicol Ferrier, Academic Psychiatry, Campus for Ageing and Vitality, Westgate Road, Newcastle, NE4 5PL, UK.

First received 28 Aug 2020

Final revision 1 Feb 2021 Accepted 2 Feb 2021

\section{Copyright and usage}

(C) The Author(s), 2021. Published by Cambridge University Press on behalf of The Royal College of Psychiatrists. This is an Open Access article, distributed under the terms of the Creative Commons Attribution licence (http://creativecommons.org/ licenses/by/4.0/), which permits unrestricted re-use, distribution, and reproduction in any medium, provided the original work is properly cited. 
warnings or 'special controls'. This change applied to use in severe depression and catatonia, but not the rarer uses in schizophrenia and mania, and is a strong endorsement of the importance of ECT for the treatment of the most serious and sometimes life-threatening conditions (Kellner 2019).

\section{ECT versus antidepressants}

In RCTs, ECT has been shown to be more efficacious than antidepressant medication in the short-term treatment of depression (UK ECT Review Group 2003). Treatment resistance does not rule out a favourable response to ECT. Patients who have failed one or more adequate medication trials have a diminished but still substantial rate of response to ECT. Dombrovski et al found a remission rate of about $50 \%$ when ECT was used to treat unipolar major depression that had not responded despite vigorous antidepressant treatment (Dombrovski 2005) and this was confirmed in another study, which reported a remission rate of $48 \%$ with ECT in resistant depression when multiple previous treatments had failed (Heijnen 2010). There is, however, a need to carry out further trials of ECT in both severe and treatment-resistant depression comparing efficacy and side-effect burden with more modern pharmacological agents and regimes.

The addition of nortriptyline to ECT enhanced the latter's efficacy with fewer cognitive side-effects (Sackeim 2009). However, more recently, Song and colleagues have adduced evidence in an indirect comparison meta-analysis that in treatment-resistant depression, the addition of an antidepressant to ECT may come at the cost of increased incidence of memory deterioration (Song 2019). Further trials on the issue are required, again using modern antidepressants with improved side-effect profiles: in the meantime, it seems prudent to avoid high doses of antidepressants during a course of ECT.

\section{High-dose ECT}

Recently, in a well-powered non-inferiority RCT, high-dose (6 times seizure threshold) right unilateral ECT was equally effective compared with bi-temporal placement ECT (Semkovska 2016). This was also the conclusion of a systematic review and meta-analysis of RCTs comparing bi-temporal with high-dose unilateral ECT (Kolshus 2017). Kellner et al (2010) demonstrated that bi-temporal ECT at given at 1.5 times seizure threshold was more rapid in effect than right unilateral ECT at 6 times seizure threshold. The cognitive effects of bilateral and unilateral ECT are discussed below. These observations have led to the recommendation that high-dose unilateral ECT should be the default choice of settings unless rapid effects are or become required (Ferrier 2019).

\section{Brief pulse and ultra-brief pulse ECT}

Brief pulse ECT has long been recognised as a more efficient stimulus for inducing seizures than sine wave ECT and one associated with fewer cognitive side-effects. More recently, interest has turned to the use of an ultra-brief pulse ECT. Tor and colleagues (2015) conducted a systematic review and meta-analysis of studies comparing brief pulse and ultra-brief pulse right unilateral ECT. They concluded that brief pulse ECT was slightly more efficacious than ultra-brief pulse in treating depression and required fewer treatment sessions, but that it led to greater cognitive side-effects. Ultra-brief pulse ECT is therefore an option for selected patients at high risk of cognitive impairment but it is clear that further research is needed to fully evaluate ultra-brief pulse right unilateral ECT.

\section{Predictors of response to ECT}

Although ECT is the most effective treatment for depression, there is little research evidence to make precise recommendations about the place of ECT within the sequence of treatments for depression. However, there is good evidence on predictors of response to ECT. Predictors of positive response to ECT include delusions and psychomotor retardation and these effects are more marked in elderly and female patients (van Diermen 2018). Another review concluded that, in addition to these factors, depressed patients who are good responders to ECT share clinical features, such as a high severity of suicidal behaviour and a more rapid response (Pinna 2018). Lin and colleagues demonstrated that early improvement in depression (after six ECT sessions) strongly predicted high response and remission rates (Lin 2017). Conversely, in a meta-analysis of available studies, individuals with treatment resistance and longer duration of depressive episode were less likely to have symptom reduction with ECT (Haq 2015). A study from Taiwan confirmed these findings and added that higher levels of pain were also associated with poor outcome (Chen 2017a). Treatment resistance does not rule out a favourable response to ECT and remission rates of about 50\% have been reported (Heijnen 2010; Kellner 2012).

\section{Relapse rates, $c-E C T$ and $m-E C T$}

Despite its effectiveness in the acute episode, without prophylactic treatment the relapse rate is extremely high (over 80\%) in the 6 months after successful ECT. In a meta-analysis of RCTs, antidepressant medication halved the risk of relapse compared with placebo in the first 6 months, with a number 
needed to treat (NNT) of 3.3 (Jelovac 2013), and there are comparable, albeit less robust, data for lithium (Rasmussen 2015).

There are also trial data showing a significant benefit for continuation ECT (c-ECT) in reducing post-ECT relapse rates (Kellner 2016). Combined pharmacotherapy and c-ECT reduced relapse rates compared with pharmacotherapy alone (Nordenskjöld 2013). This finding was confirmed in a large RCT in geriatric depression, which showed that c-ECT after remission (in the study operationalised as four c-ECT treatments followed by further ECT only as needed) was beneficial in sustaining mood improvement for most patients and better than venlafaxine plus lithium (Kellner 2016). Another RCT showed that c-ECT combined with antidepressant prolonged the duration of remission in elderly patients with psychotic unipolar depression who had responded to ECT, compared with an antidepressant alone (Navarro 2008). c-ECT is not associated with adverse memory outcomes (Brown 2014).

Maintenance ECT (m-ECT) is ECT used as a strategy to prevent further episodes or a recurrence of illness. Uncontrolled studies show that m-ECT is effective in the longer term in reducing the frequency of relapse and recurrences of depression but further controlled studies are awaited (Brown 2014). Elias and co-workers found that, in a naturalistic setting, the efficacy of m-ECT may extend over several years while cognitive functions remained largely unaffected (Elias 2014) and the latter finding was confirmed by Kirov et al (2016), who reported that repeated courses of ECT did not lead to cumulative cognitive deficits.

\section{Safe delivery of ECT}

\section{Non-cognitive side-effects}

Properly administered, ECT is generally a safe procedure; there are no absolute contraindications. In a frail elderly population in Canada, ECT was found to be a low-risk procedure, compared with endoscopy or day surgery; the most common serious adverse effects are pneumonia and falls (Blumberger 2017). It is important to perform adequate pre-treatment assessment and minimise the effect of any comorbidities; where there are any concerns about the patient's physical health, it is helpful to involve the anaesthetic team in this assessment. There are many case reports of patients with a wide variety of physical disorders being successfully treated with ECT (Ferrier 2019).

Transient, minor adverse effects are common after treatment. Data on these are published regularly by SEAN (Scottish ECT Accreditation Network 2019) and 2018 findings are shown in Fig. 1. Patients may experience headaches, muscular aches or nausea (6\%). Anorexia, weakness and drowsiness are other frequent adverse effects. Although common, these are usually mild and respond to symptomatic treatments (e.g. paracetamol for headache or ondansetron for nausea).

\section{Cognitive side-effects}

Transient disorientation is very common immediately after ECT, rarely persisting for more than 1 h. Time to reorientation in time (day of the week), place (name of the hospital) and person (name, current age, date of birth) should be recorded routinely. Longer time to reorientation is associated with more persistent memory impairment. Time to reorientation is shorter after ultra-brief pulse ECT.

Anterograde amnesia (impaired ability to remember new information from the start of ECT treatment) and impaired executive functioning may occur during the course of treatment. Semkovska $\&$ McLoughlin (2010) performed a meta-analysis of studies of objective cognitive performance following ECT, which showed that most short-term effects on anterograde memory and executive function resolved or improved from baseline within 2 weeks of the last ECT. Working memory (digit-span backwards) was not affected by ECT.

Retrograde amnesia (difficulty remembering information learned before the start of treatment), especially autobiographical amnesia (impaired ability to remember events from one's own life), is distressing to patients but is difficult to research as there is no ideal instrument for its assessment. Brief pulse right unilateral ECT carries a lower risk of causing retrograde amnesia (Kolshus 2017).

Many patients complain of difficulty in remembering after a course of ECT, with some reporting that this impairment outweighed any benefit that they gained from the treatment (Rose 2003). Subjective memory difficulties do not correlate with objective performance on cognitive tests but are associated with depression severity. The literature on subjective memory impairment after ECT has recently been reviewed by Vann Jones \& McCollum (2019). They found that in most studies patients reported an improvement in subjective memory after ECT, which correlated with improved depression ratings. One study that the authors reviewed, a retrospective analysis of 1212 medical records from the Swedish ECT treatment registry, found that about a quarter of patients reported worse subjective memory posttreatment. Longer pulse widths were associated with more complaints, as were younger age and female gender. A small number of patients complained of complete loss of subjective memory, emphasising the importance of monitoring of all patients (Brus 2017). The National Institute for 


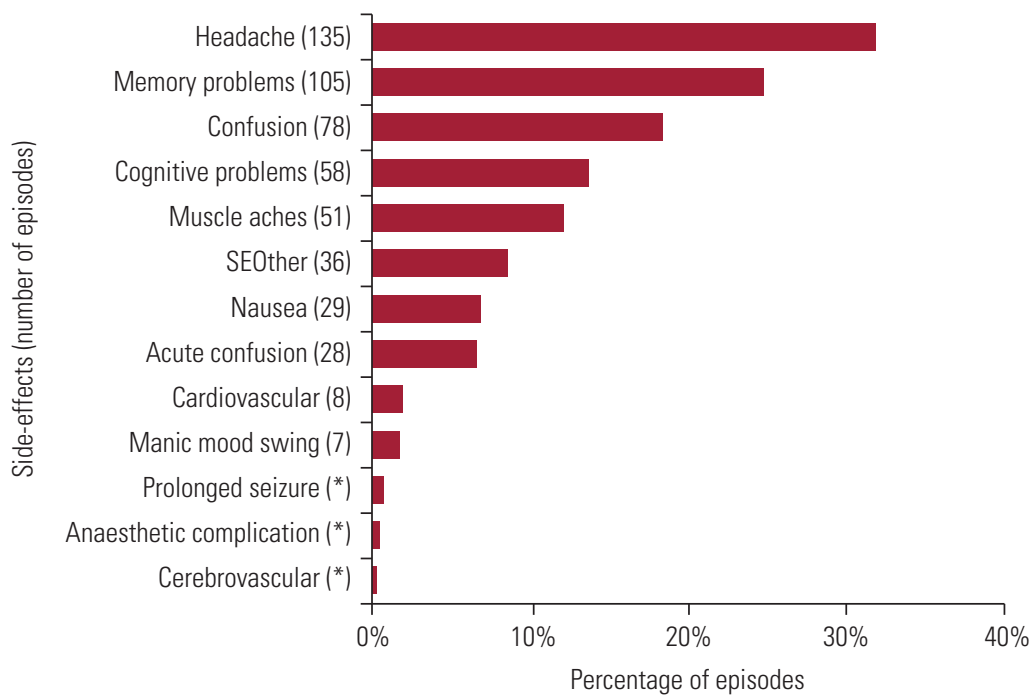

Prevalence of specific side-effects experienced within episodes: data for Scotland, 2018. Figures total more than 100\% because of the multiple-response nature of the variables examined. Cognitive side-effects are recorded under four headings: acute confusion - defined as treatment-emergent delirium, where the patient experiences confusion for a short time immediately on wakening after treatment and recorded by ECT staff; confusion - reported by the patients and occurring between treatments (e.g. on return to the ward); memory problems - short-lived autobiographical memory impairment (e.g. names, events) reported by the patient; cognitive problems - problems with orientation, attention or concentration reported by the patients or noted by staff. SEOther, other side-effects. *Side-effects are sorted in descending order of the average percentage (average number with specific side-effect divided by average number of episodes). Reproduced with permission from Scottish ECT Accreditation Network (2019).

Health and Care Excellence (NICE) (2003) recommends that cognitive function should be monitored during a course of treatment, and the Mini-Mental State Examination (MMSE) and Montreal Cognitive Assessment (MoCA) have been evaluated for this. In a study of 109 older (aged over 55 years) patients receiving ECT for depression, there was an improvement in MMSE score, which was maintained over the 6-month follow-up (Obbels 2019). There were similar findings in a study that compared the MoCA with the MMSE; the MoCA was able to detect more impairments in memory, language and visuo-executive performance (Moirand 2018).

Large-scale cohort studies in Denmark (Osler 2018) and Taiwan (Chu 2018) have found no evidence that receiving ECT is associated with any increased risk of dementia.

\section{Other neuromodulatory treatments}

\section{Transcranial magnetic stimulation}

Hardy and colleagues have summarised the use of transcranial magnetic stimulation (TMS) in an earlier BJPsych Advances article (Hardy 2016). It is now being increasingly used in clinical practice, it has few adverse effects and has proved acceptable to patients, but it is less effective that ECT in severe depression and takes longer to achieve remission (Chen, 2017b).

\section{Magnetic seizure therapy}

Production of generalised seizures is a hazard of TMS; in magnetic seizure therapy (MST), magnetic pulses are used to deliberately induce seizures. In open studies and small-scale trials, MST had comparable efficacy to ECT, with more rapid recovery and fewer cognitive adverse effects (Cretaz 2015). Large-scale clinical trials of MST against ECT are planned.

\section{Vagus nerve stimulation}

Vagus nerve stimulation (VNS) was introduced as a treatment for refractory epilepsy. It has also been used in the management of treatment-resistant depression; there are some data indicating that it may effective. However, NICE has concluded that current evidence on the safety and efficacy of VNS for treatment-resistant depression is inadequate in quantity and quality and that the procedure should be used only 'with special arrangements for clinical governance, consent, and audit or research' (National Institute for Health and Care Excellence 2020: para. 1.1).

\section{Transcranial direct current stimulation}

In transcranial direct current stimulation (tDCS), weak (0.5-2 mA) direct current is targeted to cortical areas via scalp electrodes (Borrione 2018). 
There are no major safety concerns, but the evidence for its efficacy is not robust. There is no consensus about the specific mode of administration, the number of treatments needed or the duration of effect, so NICE (2015) recommends that it should be regarded as a research procedure.

\section{Deep brain stimulation}

Deep brain stimulation (DBS) is an established procedure for several neurological disorders. It requires the implantation of stimulating electrodes in the brain, connected to a device to deliver targeted electrical pulses. Double-blind studies of DBS versus sham stimulation at the ventral capsule/ ventral striatum (VC/VS) did not show superiority for active treatment in treatment-resistant depression (Dougherty 2015; Holtzheimer 2017). A recent small $(n=6)$ trial of two different electrode placements for the treatment of obsessive-compulsive disorder was able to demonstrate relief of different symptoms with stimulation of sites in the anteromedial subthalamic nucleus and the VC/VS (Tyagi 2019).

\section{Monitoring ECT practice in the UK}

For ECT services to be able to deliver safe, effective treatment, they need to know what they should be doing. This was not the case even 25 years ago, when it would be fair to say that no one really knew what ECT clinics were doing and there was a huge variation in practice between clinics. Concern about how it was administered was considered the major threat to the continued use of ECT rather than any doubt about its therapeutic utility (Caird 2004). An editorial in The Lancet in 1981 warned that if ECT is ever legislated against or falls into disuse it will not be because it is an ineffective or dangerous treatment, it will be because [of a failure] to supervise and monitor it correctly' (Anon 1981).

The proposal for an accreditation body came about following the last national audit of ECT in 1998 (Duffett 1998), which reflected concerns from an earlier survey about deficits in the quality of administration of ECT (Pippard 1992). The first (and only overarching) NICE guidance on ECT highlighted the significance of such deficits by specifically linking efficacy and side-effects of ECT to the method of its delivery (National Institute for Health and Care Excellence 2003). Further problems were found in the area of information provision and properly informed consent for ECT, with one review finding that half of those undergoing ECT reported that they had not been given an adequate explanation (Rose 2003). These problems can be seen in the context of the time, reinforced by testimonials suggesting that many ECT clinic staff worked in isolation, with little communication with other clinics.

The steps towards providing unifying guidance to minimise such problems began with the publication of the first edition of The ECT Handbook by the Royal College of Psychiatrists in 1995, which aimed to provide theoretical references and practical guidance on running an ECT service. The National Association of Lead Nurses in ECT (NALNECT) was founded in 2002 to combat the sense of isolation experienced by ECT nurses and create a forum for them to share good practice and solutions to common challenges.

\section{The ECT Accreditation Service (ECTAS)}

ECTAS, founded in 2003, is a quality improvement network and accreditation scheme for ECT clinics across the UK and Ireland, apart from Scotland (which, as mentioned above, has its own such service, SEAN). It was the first such network in the Royal College of Psychiatrists and currently sits within the College Centre for Quality Improvement (CCQI) alongside several other networks covering a range of psychiatric services, which were subsequently developed on the basis of the ECTAS model.

The most significant impact of ECTAS has undoubtedly been to publish evidence-based standards for ECT practice and then, through a model comprising peer reviews of ECT clinics and recommendations for accreditation, to help clinics evaluate themselves against these standards. Domains for commendation in the areas of patient experience, training, documentation, and monitoring and follow-up have recently been developed to encourage clinics to strive for excellence. The standards are currently in their 15th edition (ECT Accreditation Service 2020b). As well as evolving in light of the latest evidence, the standards become more stringent with each review, so that what were once aspirational standards have become mandatory within a few years; this has undoubtedly driven up standards in ECT practice. A College audit looking at compliance against 10 ECTAS standards found little improvement in audits conducted in 1981, 1992 and 1998 but a large increase in compliance with these standards from 2004 onwards, demonstrating the impact of ECTAS (Murphy 2018).

ECTAS membership remains voluntary at present. Another extremely important function of ECTAS is to collect demographic, treatment and outcome data from member clinics on patients receiving acute and maintenance ECT, and submission of these data is an ECTAS standard. The challenge now is to capture the data on every patient 


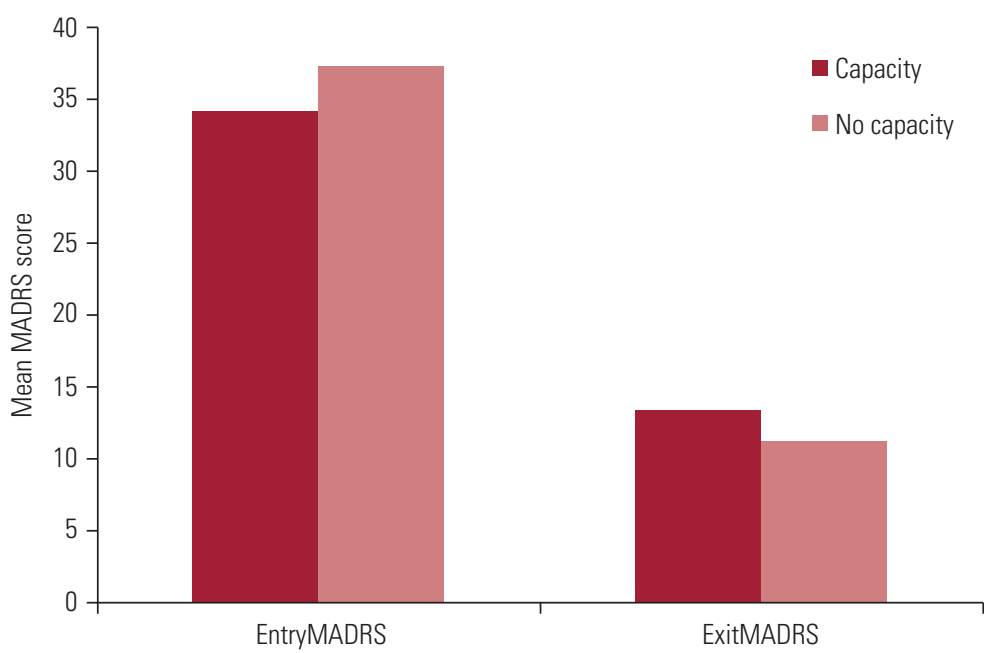

Mean scores on the Montgomery-Åsberg Depression Rating Scale (MADRS) before and after treatment for patients with and without capacity to consent to electroconvulsive treatment: data for Scotland, 2018. Reproduced with permission from Scottish ECT Accreditation Network (2019).

receiving ECT, as already happens in Scotland, where membership of SEAN is mandatory for ECT clinics and patients' treatment information is entered on the SEAN database. Technological solutions to this are being sought, as such an undertaking cannot involve duplication of work if it is to be successful; the ideal system would be a data-set to which patient data could be entered and easily copied over to one of the many electronic patient records currently in use in the regions covered by ECTAS.

\section{Development of further quality networks}

A range of physical treatments in psychiatry described above are becoming available and the natural place for many of these treatments to sit, in terms of both operational management and clinical expertise, is within ECT services, which are expanding in some places into neuromodulation services. There is therefore an opportunity to build in the success of the ECTAS approach from the start (as opposed to 65 years later in the case of ECT), whether this is applied to rTMS services or treatments with other novel psychoactive substances. Discussions are already underway to develop standards and networks in these fields and ensure that quality improvement and striving for excellence will be a founding principle for these new services.

\section{Legal and ethical issues}

The practice of giving ECT to patients who lack capacity to consent to this form of treatment has been highlighted by proposed changes in mental health legislation in England and Wales (Department of Health and Social Care 2021). Data on the outcome of ECT patients who lack capacity to consent to treatment is published each year by
SEAN in their annual report (Scottish ECT Accreditation Network 2019). Their figures consistently show that patients without capacity are more severely ill and have a better response to treatment than patients who are able to consent (Fig. 2). This reinforces the importance of making ECT available to patients who are too unwell to be able to give fully informed consent.

Issues concerning the capacity to consent to treatment have been considered at length by the Supreme Court of Victoria, Australia (PBU \& NJE v Mental Health Tribunal [2018]). The Court held that:

$$
\begin{aligned}
& \text { 'To have the capacity to give informed consent, it is not } \\
& \text { required of persons having mental illness, nor of persons } \\
& \text { not having mental illness, that they give, or are able to } \\
& \text { give, careful consideration to the advantages and disad- } \\
& \text { vantages of the treatment. It is not required that they } \\
& \text { make, or are able to make, a rational and balanced deci- } \\
& \text { sion in relation to the decision. It is enough that the } \\
& \text { person, like most people, is able to make and communi- } \\
& \text { cate a decision in broad terms as to the general nature, } \\
& \text { purpose and effect of the treatment.' }
\end{aligned}
$$

As mental health and capacity legislation in Victoria is based on the same principles as in the UK, it is likely that a British court would reach the same conclusions.

\section{Acknowledgements}

The help of Eve Blanchard and Sinead Rogers from ECTAS at the Royal College of Psychiatrists in gathering and analysing the ECTAS data-set is gratefully acknowledged, as is the assistance of SEAN and Dr Alistair Hay in reproducing Figs 1 and 2.

\section{Author contributions}

Each author was involved in the writing and the revising of this paper. 


\section{Funding}

This research received no specific grant from any funding agency, commercial or not-for-profit sectors.

\section{Declaration of interest}

None.

\section{References}

PBU \& NJE v Mental Health Tribunal [2018] VSC 564. Available from: http://www.austlii.edu.au/cgi-bin/viewdoc/au/cases/vic/VSC/2018/564. html.

Anon (1981) ECT in Britain: a shameful state of affairs. Lancet, 2: 1207-8. Blumberger DM, Seitz DP, Herrmann N, et al (2017) Low medical morbidity after acute courses of electroconvulsive therapy in a population based sample. Acta Psychiatrica Scandinavica, 136: 583-93.

Borrione L, Moffa AH, Martin D, et al (2018) Transcranial direct current stimulation in the acute depressive episode: a systematic review of current knowledge. Journal of ECT, 34: 153-63.

Brown ED, Lee H, Scott D, et al (2014) Efficacy of continuation/maintenance electroconvulsive therapy for the prevention of recurrence of a major depressive episode in adults with unipolar depression: a systematic review. Journal of ECT, 30: 195-202.

Brus 0, Nordanskog P, Båve U, et al (2017) Subjective memory immediately following electroconvulsive therapy. Journal of ECT, 33: 96-103.

Buley N, Copland E, Hodge S, et al (2017) A further decrease in the rates of administration of electroconvulsive therapy in England. Journal of ECT, 33: 198-202.

Caird H. Worrall A, Lelliott P et al (2004) The Electroconvulsive Therapy Accreditation Service. Psychiatric Bulletin, 28: 257-9.

Chen CC, Lin CH, Yang WC, et al (2017a) Clinical factors related to acute electroconvulsive therapy outcome for patients with major depressive disorder. International Clinical Psychopharmacology, 32: 127-34.

Chen JJ, Zhao LB, Liu YY, et al (2017b) Comparative efficacy and acceptability of electroconvulsive therapy versus repetitive transcranial magnetic stimulation for major depression: a systematic review and multiple-treatments meta-analysis. Behavioural Brain Research, 320: 30-6.

Chu C-W, Chien W-C, Chung C-H, et al (2018) Electroconvulsive therapy and risk of dementia: a nationwide cohort study in Taiwan. Frontiers in Psychiatry, 9: 397

Cretaz E, Brunoni AR, Lafer B (2015) Magnetic seizure therapy for unipolar and bipolar depression: a systematic review. Neural Plasticity, 2015: 521398.

Department of Health and Social Care (2021) Reforming the Mental Health Act. Department of Health and Social Care (https://www.gov. uk/government/consultations/reforming-the-mental-health-act/reformingthe-mental-health-act)

Dombrovski AY, Mulsant BH, Hasket RF, et al (2005) Predictors of remission after electroconvulsive therapy in unipolar major depression. Journal of Clinical Psychiatry, 66: 1043-9.

Dougherty DD, Rezai AR, Carpenter LL, et al (2015) A randomized shamcontrolled trial of deep brain stimulation of the ventral capsule/ventral striatum for chronic treatment resistant depression. Biological Psychiatry, 78: 240-8.

Duffett R, Lelliott P (1998) Auditing electroconvulsive therapy: the third cycle. British Journal of Psychiatry, 172: 401-5.

ECT Accreditation Service (ECTAS) (2020a) ECTAS Dataset Report (2020), Royal College of Psychiatrists, in press.

ECT Accreditation Service (ECTAS) (2020b) Standards for the Administration of ECT (15th edn) (CCOI 332). Royal College of Psychiatrists. Available from: https://www.rcpsych.ac.uk/improvingcare/ccqi/quality-networks-accreditation/ectas/ectas-standards.
Elias A Chathanchirayil SJ, Bhat $R$, et al (2014) Maintenance electroconvulsive therapy up to 12 years. Journal of Affective Disorders, 156: 228-31.

Ferrier IN, Waite J (eds) (2019) The ECT Handbook (4th edn). Cambridge University Press.

Haq AU, Sitzmann AF, Goldman ML, et al (2015) Response of depression to electroconvulsive therapy: a meta-analysis of clinical predictors. Journal of Clinical Psychiatry, 76: 1374-84.

Hardy S, Bastick L, O'Neill-Kerr A, et al (2016) Transcranial magnetic stimulation in clinical practice. BJPsych Advances, 22: 373-9.

Heijnen WT, Birkenhager TK, Wierdsma Al, et al (2010) Antidepressant pharmacotherapy failure and response to subsequent electroconvulsive therapy: a meta-analysis. Journal of Clinical Psychopharmacology, 30: 616-9.

Holtzheimer P, Husain MM, Lisanby SH, et al (2017) Subcallosal cingulate deep brain stimulation for treatment-resistant depression: a multi-site, randomized, sham controlled trial. Lancet Psychiatry, 4: 839-49.

Jelovac A, Kolshus E, McLoughlin DM (2013) Relapse following successful electroconvulsive therapy for major depression: a meta-analysis. Neuropsychopharmacol, 38: 2467-74.

Kellner CH, Fink M, Knapp R, et al (2005) Relief of expressed suicidal intent by ECT: a consortium for research in ECT study. American Journal of Psychiatry, 162: 977-82.

Kellner CH, Knapp R, Husain MM, et al (2010) Bifrontal, bitemporal and right unilateral electrode placement in ECT: randomised trial. British Journal of Psychiatry, 196: 226-34.

Kellner $\mathrm{CH}$, Greenberg RM, Murrough JW, et al (2012) ECT in treatmentresistant depression. American Journal of Psychiatry, 169: 1238-44.

Kellner CH, Husain MM, Knapp RG, et al (2016) A novel strategy for continuation ECT in geriatric depression: Phase 2 of the PRIDE Study. American Journal of Psychiatry, 173: 1110-8.

Kellner $\mathrm{CH}$, McCall WV, Spaans HP, et al (2019) The FDA final order on ECT devices, finally. Journal of ECT, 35: 69-70.

Kirov GG, Owen L, Ballard H, et al (2016) Evaluation of cumulative cognitive deficits from electroconvulsive therapy. British Journal of Psychiatry, 208: 266-70.

Kolshus E, Jelovac A, McLoughlin DM (2017) Bitemporal v. high-dose right unilateral electroconvulsive therapy for depression: a systematic review and meta-analysis of randomized controlled trials. Psychological Medicine, 47: 518-30.

Lin CH, Chen MC, Yang WC, et al (2016) Early improvement predicts outcome of major depressive patients treated with electroconvulsive therapy. European Neuropsychopharmacology, 26: 225-33.

Moirand R, Galvao F, Lecompte M, et al (2018) Usefulness of the Montreal Cognitive Assessment (MoCA) to monitor cognitive impairments in depressed patients receiving electroconvulsive therapy. Psychiatry Research, 259: 476-81.

Murphy G, Doncaster E, Chaplin R, et al (2013) Three decades of quality improvement in electroconvulsive therapy: exploring the role of accreditation. Journal of ECT, 29: 312-7.

National Institute for Health and Care Excellence (2003) Guidance on the Use of Electroconvulsive Therapy (Last updated October 2009) (Technology Appraisal Guidance TA59). NICE.

National Institute for Health and Care Excellence (2015) Transcranial Direct Current Stimulation (tDCS) for Depression (Interventional Procedures Guidance IPG530). NICE.

National Institute for Health and Care Excellence (2020) Implanted Vagus Nerve Stimulation for Treatment-Resistant Depression (Interventional Procedures Guidance IPG679). NICE.

Navarro V, Gastó C, Torres X, et al (2008) Continuation/maintenance treatment with nortriptyline versus combined nortriptyline and ECT in late-life psychotic depression: a two-year randomized study. American Journal of Geriatric Psychiatry, 16: 498-505.

Nordenskjöld A, von Knorring L, Ljung T, et al (2013) Continuation electroconvulsive therapy with pharmacotherapy versus pharmacotherapy alone for prevention of relapse of depression: a randomized controlled trial. Journal of ECT, 29: 86-92.
MCQ answers

$1 d \quad 2 b \quad 3 b \quad 4 b \quad 5 c$ 
Obbels J, Vansteelandt K, Verwijk E, et al (2019) MMSE changes during and after ECT in late-life depression: a prospective study. American Journal of Geriatric Psychiatry, 27: 934-44.

Osler M, Rozing MP, Christensen GT, et al (2018) Electroconvulsive therapy and risk of dementia in patients with affective disorders: a cohort study. Lancet Psychiatry, 5: 348-56.

Pagnin D, de Queiro V, Pini S, et al (2004) Efficacy of ECT in depression: a meta-analytic review. Journal of ECT, 20: 13-20.

Petrides G, Fink M, Husain MM, et al (2001) ECT remission rates in psychotic versus nonpsychotic depressed patients: a report from CORE. Journal of ECT, 17: 244-53.

Pinna M, Manchia M, Oppo R, et al (2018) Clinical and biological predictors of response to electroconvulsive therapy (ECT): a review. Neuroscience Letters, 669: 32-42.

Pippard J (1992) Audit of electroconvulsive treatment in two National Health Service regions. British Journal of Psychiatry, 160: 621-37.

Rasmussen KG (2015) Lithium for post-electroconvulsive therapy depressive relapse prevention: a consideration of the evidence. Journal of ECT, 3: $87-90$

Rose D, Fleischmann P, Wykes T, et al (2003) Patients' perspectives on electroconvulsive therapy: systematic review. BMJ, 326: 1363-6.

Rosenquist PB, Brenes GB, Arnold EM, et al (2006) Health-related quality of life and the practice of electroconvulsive therapy. Journal of ECT , 22: 18-24.

Sackeim HA, Dillingham EM, Prudic J, et al (2009) Effect of concomitant pharmacotherapy on electroconvulsive therapy outcomes: short-term efficacy and adverse effects. Archives of General Psychiatry, 66: 729-37.

Scottish ECT Accreditation Network (2019) Annual Report 2019: A Summary of ECT in Scotland for 2009-2018. NHS National Services Scotland.
Semkovska M, McLoughlin DM (2010) Objective cognitive performance associated with electroconvulsive therapy for depression: a systematic review and meta-analysis. Biological Psychiatry, 68: 568-77.

Semkovska M, Landau S, Dunne R, et al (2016) Bitemporal versus highdose unilateral twice-weekly electroconvulsive therapy for depression (EFFECT-Dep): a pragmatic, randomized, non-inferiority trial. American Journal of Psychiatry, 173: 408-17.

Song GM, Tian X Shuai T, et al (2015) Treatment of adults with treatmentresistant depression: electroconvulsive therapy plus antidepressant or electroconvulsive therapy alone? Evidence from an indirect comparison meta-analysis. Medicine (Baltimore), 94(26): e1052.

Spaans $H$, Sienaert P, Bouckaert F, et al (2015) Speed of remission in elderly patients with depression: electroconvulsive therapy $\mathrm{v}$. medication. British Journal of Psychiatry, 206: 67-71.

Tor PC, Bautovich A, Wang M J, et al (2015) A systematic review and meta-analysis of brief versus ultrabrief right unilateral electroconvulsive therapy for depression. Journal of Clinical Psychiatry, 76: 1092-8.

Tyagi H, Apergis-Schoute AM, Akram H, et al (2019) A randomized trial directly comparing ventral capsule and anteromedial subthalamic nucleus stimulation in obsessive-compulsive disorder: clinical and imaging evidence for dissociable effects. Biological Psychiatry, 85: 726-34.

UK ECT Review Group (2003) Efficacy and safety of electro-convulsive therapy in depressive disorders: a systematic review and meta-analysis. Lancet, 361: 799-808.

van Diermen L, van den Ameele S, Kamperman AM, et al (2018) Prediction of electroconvulsive therapy response and remission in major depression: meta-analysis. British Journal of Psychiatry, 212: 71-80.

Vann Jones S, McCollum R (2019) Subjective memory complaints after electroconvulsive therapy: systematic review. BJPsych Bulletin, 43: $73-80$

\section{MCOs}

Select the single best option for each question stem

1 Which of the following statements regarding ECT for depression is true?

a Ultra-brief pulse is the recommended mode of delivery

b Unilateral delivery of ECT is much less effective

c Treatment-resistant depression is a relative contraindication for ECT

$d$ ECT is as effective in the elderly as the middleaged

e Continuation ECT should be reserved for those with psychotic depression.

2 Which of the following is not a common transient adverse effect of ECT?

a Muscle aches

b Diarrhoea

c Memory problems

d Confusion

e Nausea.
3 Which of the following statements about cognitive effects of ECT is true?

a The Montreal Cognitive Assessment (MoCA) is of no value in assessing cognitive impairment after ECT

b Transient memory loss immediately after ECT is common

c There is an increased risk of dementia in patients treated with ECT

d Rates of cognitive impairment are similar following bilateral and unilateral ECT

e Rates of cognitive impairment are similar following brief pulse and ultra-brief pulse unilateral ECT.

4 Which of the following statements about ECTAS is false?

a ECTAS was set up partly in response to concerns about deficits in the quality of administration of ECT

b ECTAS regulates ECT services in England, Wales, Northern Ireland and the Republic of Ireland

c ECTAS publishes standards relating to the practice of ECT

d ECTAS collects data on ECT patients from member clinics

e Membership of ECTAS is currently voluntary.
5 Which of the following statements is true?

a Bi-temporal ECT is more effective than high-dose unilateral ECT

b Antidepressants given during a course of ECT have a beneficial effect on memory via improved treatment of all depressive symptoms

c Antidepressants given after a successful course of ECT halve the risk of relapse in the ensuing 6 months

d Maintenance ECT can prevent relapse over several years but at a cost of cumulative cognitive deficits

e ECT should only be used as a treatment of last resort in patients with physical comorbidities. 